\title{
Determinants of corn farmers to adapt to climate change impacts in Sagbayan, Bohol, Philippines
}

\author{
Zyra May H. Centino* and Arvin B. Vista
}

\begin{abstract}
The need to adapt to the negative impacts of climate change is urgent especially in the agriculture sector. However, there have been no published reports whether upland corn farmers are applying climate change adaptation strategies. This study sampled 91 upland corn farmers in Sagbayan, Bohol, Philippines to determine the factors affecting their decision to employ adaptations strategies. The adaptation strategies are those soil and water management and conservation techniques employed by farmers, which is modelled using binary logistic regression. The average age of the respondents was 56 years old. Respondents have been in corn production for an average period of 30 years. More than $50 \%$ of their annual household income comes from farming (PhP 25,393). Results showed that gender, farm income, total land used in farming and value of farm assets were the determinants of farmers' use of adaptation strategies. Overall, corn farmers are knowledgeable of the impacts of climate change; however, employment of adaptation strategies is minimal. Hence, intervention should focus on programs that will increase probability of farmers employing adaptation strategies. Such programs may include farm-to-market roads to minimize post-harvest losses, setting of farmer field school and information drive.
\end{abstract}

Keywords: adaptation strategies, climate-induced impacts, upland corn farmers, soil and water conservation

\section{INTRODUCTION}

Climatic conditions have deviated from the norms. These deviations are shown in the change in temperature, precipitation and greenhouse gases (GHGs) concentrations (Intergovernmental Panel on Climate Change 2007). In the Philippines, data trend from 1960 up to the present show increasing temperature,

Department of Economics, Visayas State UniversityVisca, Baybay City, Leyte

Department of Applied and Agricultural Economics University of the Philppines Los Baños College, Laguna

\footnotetext{
* Corresponding Author. Address: Department of Economics, Visayas State UniversityVisca, Baybay City, Leyte; Email: zyramay.centino@vsu.edu.ph

DOI: $10.32945 /$ atr 4027.2018
} 
sea level rise and occurrence of extreme climate events - trends that are consistent with global scenarios (Jabines et al 2007, Yanagi \& Akaki 1994). It is further reported that the mean temperature in the country indicate an increase of $0.648^{\circ} \mathrm{C}$ or an average of $0.0108^{\circ} \mathrm{C}$ per year. Analysis of trends of tropical cyclones passing the Philippine Area of Responsibilities (PAR) revealed a yearly average of 20-21 tropical cyclones. The number of tropical cyclones entering or passing PAR has not increased, but there is a very slight increase in the intensity of tropical cyclones with maximum sustained winds of greater than $150 \mathrm{kph}$ and above. Moreover, the analysis on tropical cyclone passage over the main islands of the country (Luzon, Visayas and Mindanao), the 30-year running means show that there has been a slight increase in the Visayas during the 1971-2000 period as compared with the 1951-1980 and 1960-1990 periods (PAGASA 2011).

The adverse effects of climate variability are visible and felt especially in the agricultural sector. In 2005, farmers experienced droughts and floods that caused a total damage of PhP 838 million (Department of Agriculture [DA] 2011). In particular, corn productivity declined by as much as $6 \%$ due to fluctuations in weather. Moreover, it has been reported that climate variability will continue to reduce agricultural yield. For instance, the estimated rice yield reduction coefficients ranges from 1\%-100\% (SEARCA 2005 as cited by Vista 2014). Losses due to typhoons and floods were estimated to range from $2.6 \%-62.54 \%$. Moreover, damages brought by drought were estimated to be at $1.5 \%$, while pests and disease incidents may cause a yield loss of up to $10 \%$. In addition, corn yield reduction due to typhoon may reach up to $70 \%$, while flooding scenarios can totally devastate corn farming areas.

In the province of Bohol, Philippines, corn (Zea mays) is a well-liked crop next to rice (Oryza sativa). Average palay and corn production in the province is at 2.88 and $0.86 \mathrm{t}$ ha/season, respectively (Bohol Provincial Agricultural Profile 2008). Most of these are mainly for home consumption. In fact, the average per capita consumption per year of these two important crops is at $85.28 \mathrm{~kg}$ for rice and $8.74 \mathrm{~kg}$ for corn. However, it is worthy to note that just like other agricultural venture, rice and corn production in the area is greatly affected by climate disturbances. For instance, when El Niño hit the province in 2005, corn production decreased from its year 2004 level of 13,831 t to only $11,690 t$, a 15\% reduction (PGB ELA 2013).

The Municipality of Sagbayan is one of the top corn producing municipalities in the province of Bohol (Figure 1). Farmers in Sagbayan consider corn farming as their main source of living. As affirmed by the locals, corn cereal takes a big part of the Boholano diet especially in the uplands because it is highly available and affordable. Aside from its ability to substitute rice as staple food in the province, corn is also commonly used as feeds for their backyard livestock. Upland corn farmers admitted that corn production is their main fallback whenever they experience losses in rice farming due to climate extremes.

Considering the importance of corn farming in Sagbayan and the enduring threats brought by climate change, the need to assess and determine how upland corn farmers try to mitigate the devastating effects of climate change is vital. Studies on the different adaptation strategies employed by the farmers and identifying the factors that may have influenced farmers to respond to climate change impacts are stepping stones for addressing the problem.

Although, there are many adaptation and mitigation options addressing the impacts of climate change, there have been few reports whether upland corn 
Determinants of corn farmers' to adapt to climate change impacts

farmers are employing such and what could have been the important factors that caused farmers to employ adaptation strategies. This paper reports the significant factors that may cause farmers to become climate change adaptive.

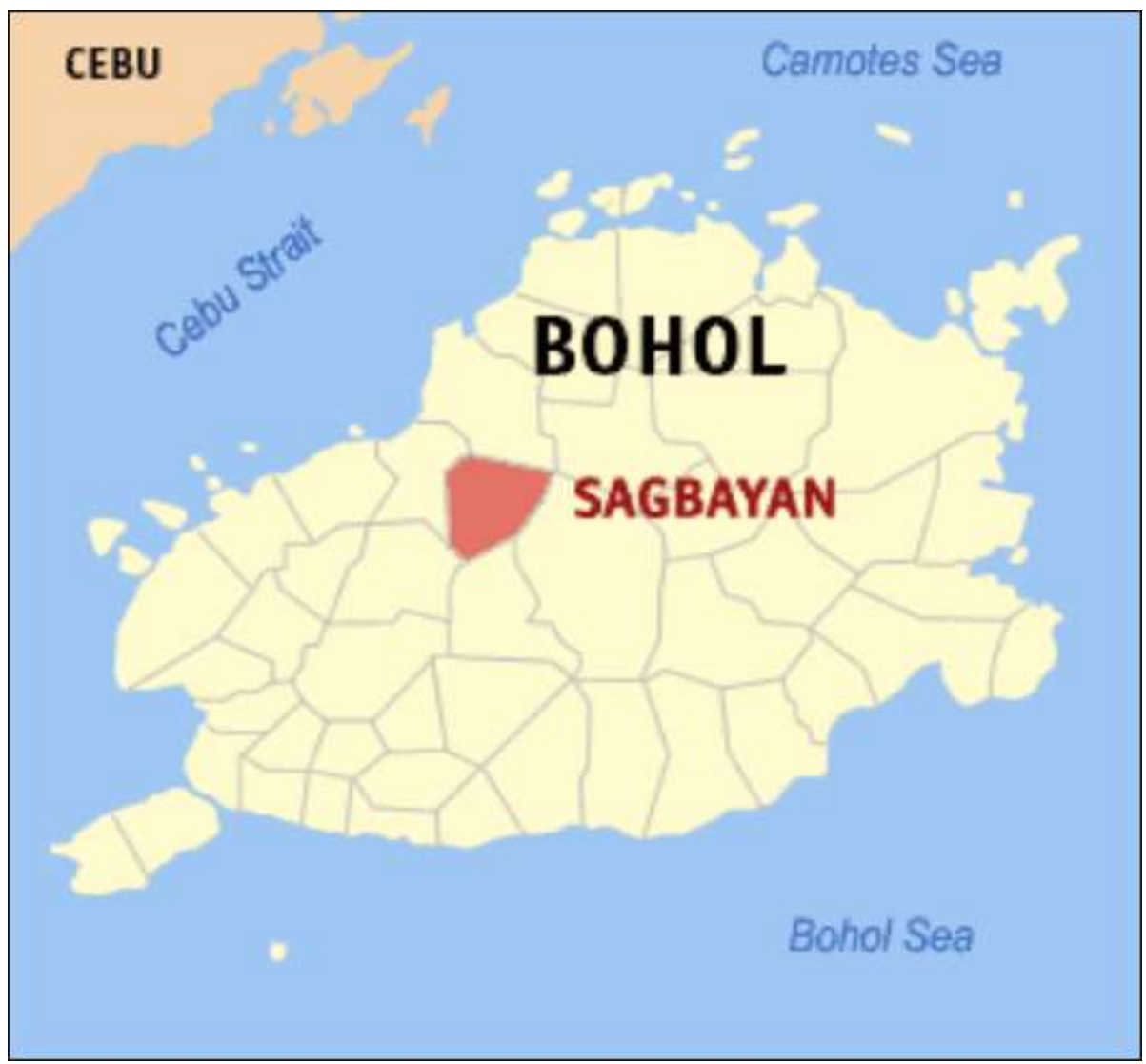

Figure 1. Location of Sagbayan, Bohol (Source: google map)

\section{MATERIALS AND METHODS}

\section{Sampling Procedure and Data Collection}

Stratified sampling by barangay was employed in the study. The top three barangays with most number of corn farmers were considered and the sample size was determined following Slovin's formula:

$$
n=\frac{N}{1+N(e)^{2}}
$$

\footnotetext{
'Slovin's, introduced by Michael Slovin in 1960, is a sampling technique used statistically so that selected samples are unbiased.
} 
where $n$ is the sample size, $N$ is the population size and the $e$ is the level of precision. The level of precision is sometimes called the sampling error. This is the range in which the true value of the population is estimated to be. The value is often expressed in percent form (eg, \pm 5 percent). In this study the level of precision is $5 \%$. The computed sample size $n$ was allocated proportionally in the selected barangays $\left(n_{1}, n_{2}, n_{3}\right)$. Simple random sampling without replacement was conducted to identify farmer respondents within each stratum.

The study used primary and secondary data. Primary data, collected through face-to-face survey using pre-tested interview schedule were: socio-economic and farm characteristics of the respondents, land use pattern, farm labor allocation, 2016 adaptation schemes employed by farmer-respondents and how they perceived climate change in their farming decisions.

Secondary data such as description of the study area, farming systems and other relevant information were gathered from secondary sources such as previous surveys, literature, and expert opinions, research reports from various institutions, government offices and agencies (eg, DA, Provincial Planning and Development Office [PPDO] Bohol, etc).

\section{Data Analysis}

Binary logistic regression analysis was employed to examine the factors affecting farmer's decision to employ soil and water management and conservation measure as their adaptation strategies for climate change. This adaptation strategy was taken as the dependent variable since this is the common method employed by farmers. Although there were other adaptation measures employed by farmers in the study, it did not satisfy the sample size requirement for a regression analysis. In this analysis, a farmer is classified as adopter $(=1)$ if he/she is employing soil and water management and conservation measure as his/her adaptation strategies. On the other hand, one is considered non-adopter $(=0)$ if he/she is not using the said adaptation measure in his/her farming activities. In a logistic model, the probability, $P_{i}$ of farmer to apply adaptation schemes in their crop management practices is as follow:

$$
P_{i}=\frac{\exp ^{Z_{i}}}{1+e x p^{Z_{i}}}
$$

where $Z_{i}$ is a random variable that predicts the probability of the $i_{t h}$ farmer to apply adaptation schemes in crop production and is given as:

$$
Z_{i}=\ln \frac{P_{i}}{1-P_{i}}=\beta_{o}+\sum_{n-1}^{n} \beta_{n} X_{i j}
$$

where $\beta_{i}$ is an unknown vector of parameters, $X_{i}$ is the identified vector of factors contributing to the decision to apply adaptation and mitigation schemes in the production process. The unknown parameter $\beta_{i}$ associated with each contributing factor $X_{i}$ is determined by an iterative process that makes use of a maximum likelihood estimate (Iqbal et al 2006). 
Determinants of corn farmers' to adapt to climate change impacts

The final form of the loaistic model is:

$$
Z_{i}=\beta_{0}+\beta_{1} X_{1 i}+\beta_{2} X_{2 i}+\ldots \ldots \beta_{n} X_{n i}
$$

Since the $\beta$ parameters are assumed unbiased and normally distributed, an analogue of Student's t-test is employed as a test of the significance of the regression. The significance of the coefficients of the variables present in the logistic model can be tested using a log-likelihood ratio test assuming $a^{2}$ data distribution (Pindyck \& Rubinfeld 1981, Sharma 1997). Given the results of the correlation analysis, the logit model was then specified as follows:

$$
\begin{aligned}
Z_{i} & =\beta_{0}+\beta_{1} \text { educat }+\beta_{2} \text { farmincome }+\beta_{3} \text { tlauf }+\beta_{4} \text { recgen }+\beta_{5} \text { totalnonfarm } \\
& +\beta_{6} \text { recacvcre } 2+\beta_{7} \text { FASSETVAL }+\beta_{8} \text { trust }+u
\end{aligned}
$$

Given the model specification above, multicollinearity test was conducted to check whether there exists significant correlations between independent variables. For the multicollinearity test, the Variance Inflation Factor (VIF) was computed. This estimates how much the variance of a coefficient is "inflated" because of linear dependence with other predictors (Allison 2012). As a rule of thumb, VIF values should be lesser than 10 to safely ignore a multicollinearity problem. As shown in Table 1 , the VIFs were less than 10 , hence multicollinearity in the model is not a problem.

Table 1. Multicolinearity test result

\begin{tabular}{llcc}
\hline Variable & \multicolumn{1}{c}{ Description } & VIF & 1/VIF \\
\hline tlauf & Total land area used in farming & 1.41 & 0.710573 \\
recgen & Gender & 1.27 & 0.789806 \\
fassetval & Total market value of farm & & \\
& assets Owned by the farmers & 1.25 & 0.798189 \\
trust & Trust in institutions & 1.25 & 0.799861 \\
recacvcre2 & Availment of credit & 1.17 & 0.855257 \\
farmincome & Total farm income & 1.13 & 0.887040 \\
educat & Educational attainment of & & \\
& farmer & 1.12 & 0.896695 \\
totalnonfarm & Total non- farm income & 1.07 & 0.935403 \\
\hline Mean VIF & & 1.21 & \\
\hline
\end{tabular}

Heteroskedasticity test was employed to determine if the error terms do not have constant variance. In this regard, the Breusch-Pagan /Cook-Weisberg test was used to check whether heteroskedasticity is a problem in the logit model. This tests the null hypothesis that the error variances are all equal against the alternative that the error variances are multiplicative function of one or more variable (Williams 2015). If the Chi-squared value is significant then the null hypothesis of homoscedasticity is rejected and heteroskedasticity is assumed. Results showed that the Chi-squared value $\left(x^{2}=0.75\right)$ is not significant (Prob $\left.>x^{2},=0.3879\right)$ and so heteroskedasticity is not a problem in the logit model. All data analyses were conducted using SPSS and Stata. 
Centino \& Vista

\section{RESULTS AND DISCUSSION}

\section{Farmer and Farm Related Information}

Ninety-one corn farmers from Sagbayan, Bohol served as the respondents of the study. Many (67\%) of them were considered non-adopters. The remaining $33 \%$ were adopters. A farmer is considered an adopter in this study if he/she is employing soil and water conservation and management technique (include activities like manual watering of corn plants and soil cultivation) as his/her adaptation strategies to cope with the impacts of climate change. The said strategy was chosen among others because it is the only climate change coping mechanism that satisfies the requirement for a logit regression analysis.

Respondents possessed the following key characteristics: majority (55\%) were male and most were married (93\%). Their average age was 56 years, which suggests that they were approaching senior years $(\geq 60)$. The average household size was around five members. In terms of educational attainment, they finished six years of formal schooling on the average. They had been farming for an average of 32 years.

The average annual household income was very low at PhP 48,679 (PhP55 is equal to about US\$1), which was composed of farm income (PhP 25,393), non-farm income (PhP 21,729) and off-farm income (PhP 1,557). The results confirmed that indeed the main source of living among the selected farmer respondents was farming.

The average total land holdings of respondents was $1.59 \mathrm{ha}$. More than $95 \%$ of these land holdings ( $1.52 \mathrm{ha}$ ) were considered agricultural land but only 1.12 ha were used in their actual farming venture (Table 2). This implies that there are still potential areas that can be cultivated. Respondents reported that more than $50 \%$ of their farming area was devoted to corn production and the rest was for other plants, which may serve as their fall back whenever they acquire losses in their corn farming due to climate disturbances. These crops were lowland and upland rice, cassava, sweet potato, vegetables and fruit trees. Noticeably, farmer adopters devoted a bigger portion of their farm area to corn farming than non-adopters (78.23\% and $50.83 \%$, respectively). This suggests that most farmer adopters were dependent on corn production as source of farm income. Hence, there is higher motivation to combat the devastating effects of climate change impacts since their main source of income is at risk.

Table 2. Total land area (ha) cultivated by farmer respondents

\begin{tabular}{lcccccc}
\hline \multirow{2}{*}{ Item } & \multicolumn{6}{c}{ Type of Respondent } \\
\cline { 2 - 7 } & \multicolumn{2}{c}{ Adopter } & \multicolumn{2}{c}{ Non-adopter } & \multicolumn{2}{c}{ Total } \\
\cline { 2 - 7 } & Mean & SE & Mean & SE & Mean & SE \\
\hline Land holdings & 1.59 & 0.28 & 1.59 & 0.20 & 1.59 & 0.16 \\
Agricultural land & 1.58 & 0.29 & 1.45 & 0.51 & 1.52 & 0.35 \\
Area use in farming & 1.50 & 0.29 & 0.92 & 0.08 & 1.12 & 0.12 \\
\hline Note: SE is standard error & & & & & &
\end{tabular}


Determinants of corn farmers' to adapt to climate change impacts

In terms of tenurial status, majority of the farmers in the area were owner operators (64\%) and the remaining were tenants (30\%) and leaseholder (6\%). Most (84\%) of them used traditional variety of corn while a small proportion experimented other varieties like hybrids, open pollinated variety (OPV) and sweet corn. This preference of the farmers to traditional variety may be attributed to the eating quality of the variety since their corn produce is mainly for home consumption.

Many of the respondent farmers claimed that they possess important farm tools like plow (35\%) and farm work animals (20\%). Moreover, a few said that they own trailers (8\%), four wheel tractors (3\%), storage area/bodega (3\%) and threshers $(2 \%)$. It can be discerned that farmers in the area are using traditional tools in farming, which may be attributed to their low levels of income and small-scale farms.

\section{Institution Related Information}

Institutions referred to in this study are the following: credit sources, cooperatives, volunteer groups called bayanihan and government programs. Many (71\%) of the corn farmers reported that they were knowledgeable of different credit sources but only (23\%) of them availed of credit. There were only a few members of cooperatives in the area (18\%). They simply were not interested to join cooperatives. However, results show that the spirit of bayanihan still lingers in the place of study. There were $7 \%$ who were active members of bayanihan groups groups, while others were not knowledgeable about its existence. In terms of participation of corn farmers in the different government programs (eg Bridging Program for the Filipino Family or 4Ps, women's organization, training programs for farmers, seed distribution and subsidized fertilizer program), a huge proportion $(68 \%)$ claimed that they were not aware about those programs while only $18 \%$ were able to avail of the programs.

Farmers were allowed to designate a trust value for the institutions around them. This was done by rating the components of trust from 1-10 with10 being the highest. The identification of the different components of trust was patterned after the works of Burnett et al (2008). All of the respondents were consistent in their trust scores in each component to be more than 5 (Table 3 ). The overall trust rating for the institutions was 7.36.

Table 3. Institutions' trust ratings by farmers in Sagbayan, Bohol, 2012

\begin{tabular}{lcccccc}
\hline \multirow{2}{*}{ Components } & \multicolumn{6}{c}{ Type of Respondent } \\
\cline { 2 - 7 } & \multicolumn{2}{c}{ Adopter } & \multicolumn{2}{c}{ Non-adopter } & \multicolumn{2}{c}{ Total } \\
\cline { 2 - 7 } & Mean & SE & Mean & SE & Mean & SE \\
\hline Leadership & 6.68 & .70 & 7.87 & 0.45 & 7.46 & 0.38 \\
Expertise & 6.94 & 0.69 & 7.67 & 0.45 & 7.42 & 0.38 \\
Transparency & 6.45 & 0.69 & 7.88 & 0.44 & 7.40 & 0.38 \\
Listening/ consultation & 6.77 & 0.70 & 7.67 & 0.45 & 7.36 & 0.38 \\
Efficiency & 6.77 & 0.71 & 7.57 & 0.47 & 7.30 & 0.39 \\
Government structure & 6.52 & 0.72 & 7.70 & 0.45 & 7.30 & 0.39 \\
Accountability & 6.52 & 0.70 & 7.68 & 0.46 & 7.29 & 0.39 \\
Overall Trust Rating & $\mathbf{6 . 6 6}$ & $\mathbf{0 . 7 0}$ & $\mathbf{7 . 7 2}$ & $\mathbf{0 . 4 4}$ & $\mathbf{7 . 3 6}$ & $\mathbf{0 . 3 8}$ \\
\hline
\end{tabular}

Note: SE is standard error 
Farmers' Perception of Climate Change and its Impacts

Farmers' knowledge of climate change and its impact is important in building a model for the factors affecting farmers' decision to apply adaptation strategies. Hence, farmers were asked about their sources of climate information, their perception about climate change and its aftermath and most importantly their actions on the existence of climate variability as it affects their ultimate source of living. Based on the results, the top three sources of climate information were the television ( $86 \%)$, the radio ( $76 \%$ ), followed by information from elders $(11 \%)$.

Meanwhile, the perceptions of farmers about climate change and its effects were assessed using a 10-item quiz type method. There were ten questions under each topic and the farmers' scores were generated. The scores served as an index for climate change and climate change impacts perception. Results suggest that farmers are knowledgeable about climate change and its adverse effects as manifested by the scores (5.54 and 5.45 respectively, Figure 2). Majority agreed that they have observed unusual changes in climate and its negative impacts.

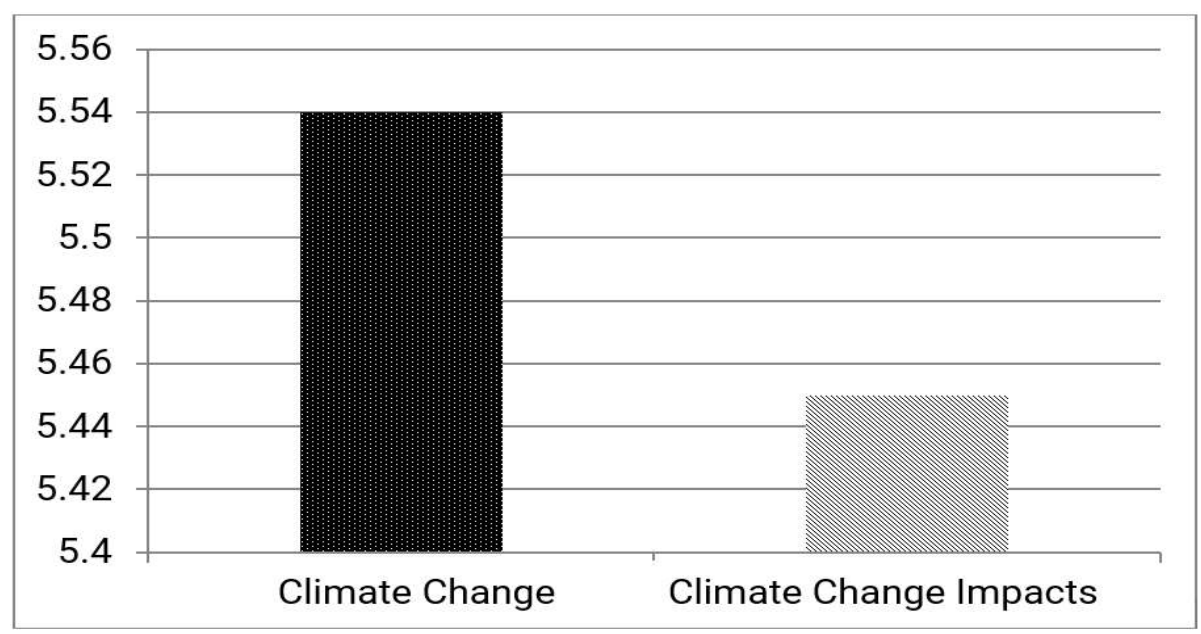

Figure 2. Farmers' knowledge and perception about climate change and its impacts in Sagbayan, Bohol

\section{Climate Change Adaptation Strategies Employed by Corn Farmers}

A few farmers were employing adaptation strategies for climate change (Table 4). However, there were few individuals who provided information related to their adaptation strategies. Their actions depend on the kind of climate disturbance. For instance, when there is a possibility of drought, the most common adaptation scheme is to perform soil and water management and conservation activities (12\%), changing cropping pattern (4\%) and adjusting cropping calendar (1\%). Meanwhile, when a typhoon is coming, a few of them would incorporate the following adaptation strategies: soil and water management and conservation means $(21 \%)$ and changing cropping calendar $(7 \%)$. 
Determinants of corn farmers' to adapt to climate change impacts

Table 4. Adaptation strategies employed by corn farmers by type of climate extreme in Sagbayan, Bohol, 2012

\begin{tabular}{|c|c|c|}
\hline \multirow{2}{*}{ Adaptation Strategies $^{a}$} & \multicolumn{2}{|c|}{ Frequency } \\
\hline & $\mathrm{n}$ & $\%$ \\
\hline \multicolumn{3}{|l|}{ Drought } \\
\hline Soil and water management and conservation & 11 & 12 \\
\hline Change in cropping pattern & 4 & 4 \\
\hline Adjust cropping calendar & 1 & 1 \\
\hline \multicolumn{3}{|l|}{ Typhoon } \\
\hline Soil and water management and conservation & 19 & 21 \\
\hline Adjust cropping calendar & 6 & 7 \\
\hline Change in cropping pattern & 1 & 1 \\
\hline
\end{tabular}

${ }^{a}$ multiple response

Soil and water management and conservation measures were used to cope with climate change during drought. These include manual watering of plants and soil cultivation. During typhoons, soil and water management and conservation type of adaptation means building temporary canal to allow water to flow continuously, soil cultivation and building temporary barriers to prevent damages on corn brought by strong winds.

\section{Determinants of Farmers' Decision to Employ Adaptation Strategies with Climate Change Impacts}

The binary logistic regression analysis was employed to examine the factors affecting farmers' decision to use adaptation strategies, specifically soil and water management and conservation measure, to negate the devastating effects of climate change. This adaptation strategy was taken as the dependent variable since this is the common practice employed among respondent farmers. Although there were other adaptation measures employed by farmers in the study, it did not satisfy the sample size requirement for a regression analysis. In this analysis, a farmer was classified as adopter $(=1)$ if he/she was employing soil and water management and conservation measure as his/her adaptation strategies. On the other hand, one was considered non-adopter $(=0)$ if he/she was not using the said adaptation measure in his/her farming activities. The logistic model was significant at $5 \%$ level. This implies that all coefficients taken together in the model are different from zero and that the variables included in the model were able to explain the variation of the data. The model correctly predicted the farmers' decision to employ soil and water conservation and management as their adaptation strategy $37.74 \%$ of the time.

Table 5 shows the independent variables together with their maximum likelihood coefficient estimates, standard error and marginal effects. Although the logistic coefficients cannot be read as regular OLS coefficient, it is the marginal effects that are used to explain how the variation of the factors included in the model affects the decision of farmer respondents to employ climate change impacts adaptation strategies. 
Table 5. Factors affecting farmers' decision to employ adaptation strategies in corn farming using binary logistic regression, Sagbayan, Bohol, 2012

\begin{tabular}{lrrr}
\hline \multicolumn{1}{c}{ Variables } & Coefficient & $\begin{array}{c}\text { Standard } \\
\text { Error }\end{array}$ & $\begin{array}{c}\text { Marginal } \\
\text { Effects }\end{array}$ \\
\hline Dummy Variables & & & \\
$\quad$ gender & -1.507419 & 0.599126 & $-0.346094^{\star \star}$ \\
$\quad$ credit availment & 0.152099 & 0.736571 & 0.361776 \\
Educational attainment & 0.016690 & 0.140851 & 0.003972 \\
Farm income & 0.000010 & 0.000006 & $0.000003^{\star}$ \\
Total land area used in farming & 1.055097 & 0.443965 & $0.247916^{\star *}$ \\
Trust in institutions & -0.085477 & 0.078903 & -0.200844 \\
Non-farm income & 0.000005 & 0.000006 & 0.000001 \\
Value of farm assets owned & 0.000077 & 0.000005 & $0.000018^{\star}$ \\
\hline
\end{tabular}

"significant at $5 \%$, "significant at $10 \% \mathrm{n}=91$

Predicted farmers decision to employ soil and water conservation and management as adaptation strategy $=37.74 \%$

The predictors (total land area used in farming, farm income and farm asset value) were statistically significant and positively related with the dependent variable. Meanwhile, the gender variable ( $1=$ male) appeared to be significant but has negative association with the dependent variable. The gender variable was found to be significant at $5 \%$ level with a negative marginal effects $\left(-0.346094^{* *}\right)$. This implies that the probability of women farmers to employ adaptation strategies is higher by $35 \%$ compared to men. This goes to show that women farmers in the area had important roles to perform in the corn production sector of the study area. In fact, many of the activities in the farm are being performed and managed by. Women farmers in the area were usually in-charge of important farming matters such as ensuring the timing of farm activities from plowing to harvesting and seeking funds for the farm operations. Women are known to be highly dependent on land and natural resources for livelihood generation making them highly vulnerable to climate change impacts (Ekpo \& Agu 2014).

Total land area used by farmers in their farming operations was significant at $5 \%$ with a positive marginal effects equivalent to $0.247916^{* *}$. This means that the probability of the respondents to adapt to the effects of climate change increases by $25 \%$ when the area used in farming increases by a hectare, other things being the same. This might be due to the fact that the risk of losing an agricultural venture is high with large areas used in farming when climate change impacts will prevail. The farmers cannot afford to lose their corn farming because it is their main source of living and their staple diet. This motivated them to do everything it takes just to have returns from their venture. Thus they applied climate change impacts adaptation strategies.

The value of farm assets in this study refers to the market price of tools and equipment used in farming by farmer respondents including farm work animals. At $10 \%$ level of significance, the model suggests that there exists a positive relationship between the decision to adapt to climate change impacts and the value of farm assets owned and used by farmers $\left(0.000018^{*}\right)$. This infers that the higher the market value of tools and equipment the more likely farmers were to act on climate change by employing adaptation strategies. Specifically, it implies that for every additional peso value of farm asset of the farmer respondents, the probability 
Determinants of corn farmers' to adapt to climate change impacts

of applying adaptation strategies in corn farming increases by $0.00018 \%$. Farm assets are highly liquid and can easily be converted to cash by selling or pawning them.

Furthermore, farm income was a significant factor affecting farmer's decision to employ climate change impacts adaptation strategies $\left(0.000003^{*}\right)$. The results suggest that every peso increase in the farm income would result to an increase in the probability of employing soil and water conservation and management as adaptation strategy by $0.00003 \%$. This is expected since higher farm income increases the capability of farmers to finance adaptation strategies.

\section{CONCLUSION AND RECOMMENDATIONS}

Sagbayan, Bohol corn farmers are knowledgeable about climate change and its adverse effects. Majority of them have observed unusual changes in climate and the negative impacts of such changes. However, majority of the farmers are still not employing adaptation strategies to address the impacts. Having knowledge about adaptation strategies is not sufficient to influence of farmers to use such strategies in their farms. In this regard, there should be prioritization of adaptation strategies that will increase the probability of adoption of soil and water management and conservation technique.

Women farmers adopted adaptation strategies more than male. Women's contributions are indeed inevitable and necessary in the operations of their corn farming and in their family as well. The government and women advocates may help build an organization that will promote women participation in social enterprises. Social enterprises of today's world were found to boost the morale of women workers because aside from the opportunity to earn more, most importantly, these women workers feel their importance in the society.

The bigger the farm area allocated to corn farming and the higher the farm income, the higher is the probability of adoption of climate change adaptation strategies. Hence, programs that would increase farm income may have positive correlation with increased adoption of climate change adaptation strategies. For example, minimizing losses from post-harvest thru investments in better farm to market roads is needed in areas far from the town proper like, Brgy. San Isidro of Sagbayan, Bohol. Likewise, setting-up of a farmer field school and information drive thru different media forms (eg, television, radio, newspaper) can be pursued so that good agricultural practices are shared with corn farmers. This can be coupled with capability and capacity enhancement of municipal agricultural officers and extension agents. When farm income increases, then farmers have additional income for possible investment in farm assets. This is expected given that higher value of farm assets of farmers is associated with the likelihood to employ adaptation strategies. 
Centino \& Vista

\section{REFERENCES}

Assessment of Impacts and Adaptations to Climate Change (AIACC) Project. 2007. Draft Final Report on Climate Change Vulnerability and Adaptation in Developing Country Regions, A Global Environment Facility Enabling Activity in the Climate Change Focal Area Project No. GFL-2328-2724-4330

Allison P. 2012. When Can You Safely Ignore Multicollinearity? Retrieved Oct. 11, 2015, from http://statisticalhorizons.com/multicollinearity

Bohol Provincial Agricultural Profile. 2011. (retrieved from http://afmis.da.gov.ph/index.php/component/docman/doc_download/1610 -bohol-provincial-agricultural-profile.html on October 10, 2015

Burnett M, Tsang S, Studer S, Hills P \& Welford R. 2008. Measuring Trust In Government: A Hong Kong Perspective. International Public Management Review, 9(2):107-125

Department of Agriculture (DA), Philippines. 2011. Annual Report. (retrieved from http://www.da.gov.ph/images/PDFFiles/AnnualReport/2011_AR/2011_Annu al_Report.pdf on October 30, 2015

Department of Agriculture (DA). 2013. Sagbayan, Bohol Corn Road Map: Municipality of Sagbayan, Bohol, Philippines

Food and Agriculture Organization (FAO). 2007. FAOSTAT agriculture data Retrieved August 26, 2013, from Food and Agriculture Organization http://faostat.fao.org

Intergovernmental Panel on Climate Change (IPCC). 2007. A summary report for policy makers in: Climate Change 2007: The Scientific Basis. Working Group I. Contribution to the Intergovernmental Panel on Climate Change Fourth Assessment Report. Cambridge University Press, Cambridge. Khanal, R.C. 2009. Climate Change and Organic Agriculture. Agriculture and Environment, 10:100-110

Iqbal SM, Ireland CR \& Rodrigo VHL. 2006. A logistic analysis of the factors determining the decision of small holder farmers to intercrop. A case study in volving rubber - tea intercropping in Sri Lanka. Agricultural Systems, 87(3):296-312

Jabines A and Inventor J. 2007. The Philippines: A Climate Hotspot Climate Change Impacts and the Philippines Greenpeace Southeast Asia, Climate and Energy Campaign

Kisner C. 2008. Climate Change in Thailand: Impacts and Adaptation Strategies (retrieved from http://www.climate.org/topics/internationalaction/thailand.htm on Oct. 2, 2011

Logroño ML, Lopez EL \& Alejandro F. 1996. Maize Seed Situation in the Philippines: A Country Report. Philippine Journal of Crop Science, 21(3):61-70

Philippine Atmospheric, Geophysical \& Astronomical Services Administration (PAGASA). 2011. Climate Change in the Philippines. Agham Road, Diliman, Quezon City Philippines: DOST-PAGASA Climatology and Agrometeorology Division (CAD) Retrieved from www.pagasa.dost.gov.ph

Philippine Statistics Authority (PSA). 2013. Philippine Agriculture in Figures. Retrieved October 30, 2015 from http://countrystat.psa.gov.ph/?cont=3

Pindyck RS and Rubinfeld DL. 1981. Econometric Model and Economic Forecasts: McGraw-Hill Education (ISE Edns) 
Determinants of corn farmers' to adapt to climate change impacts

Provincial Government of Bohol (PGB), Executive Legislative Agenda (ELA). 2013. Volume 1. (retrieved from http://bohol.gov.ph/data_directory/ index.php??=Executive_Legislative_Agenda_(ELA)_2010-2013 on October 11, 2015)

Provincial Planning and Development Office (PPDO) of Bohol. 2016. Bohol Base Map Retrieved October 5, 2016, from http://www.ppdobohol.Igu.ph/municipallinks/

Sharma VR. 1997. Environmental and Engineering Geophysics (1st edn). UK: Cambridge University Press

Vista AB. 2014. Simulating Climate-Induced Impacts on Philippine Agriculture Using Computable General Equilibrium Analysis. Journal of International Society for Southeast Asian Agricultural Sciences, 20(1):16-28

Yanagi T and Akaki T. 1994. Sea Level Variation in the Eastern Asia. Journal of Oceanography, 50:643-651. (retrieved from https://www.terrapub.co.jp /journals/JO/pdf/5006/50060643.pdf on August 10, 2012)

Williams R. 2015. Heteroskedasticity. Retrieved from http://www3.nd. edu/ rwilliam/ 